\title{
Intraepithelial haemorrhage of the oesophagus: a terminal event in haematological disorders
} Michio Shimizu, Takayuki Matsumoto, Mitsuyoshi Hirokawa, Yasumasa Monobe,
Mitsuo Iida, Toshiaki Manabe
Hokkaido University Hospital, Sapporo, Japan:

Department of Surgical Pathology M Shimizu

Kawasaki Medical School, Okayama, Japan:

Department of Medicine (Division of Gastroenterology)

T Matsumoto

M Iida

Department of Pathology

M Hirokawa

Y Monobe

T Manabe

Correspondence to: Dr Michio Shimizu, Department of Surgical Pathology, Hokkaido University Hospital, North 14, West 5, Kita-ku, Sapporo 060-8648, Japan; email: mshimizu@med.hokudai.ac.jp

Accepted for publication 17 June 1998 have been proposed for oesophageal haematoma. One occurs in patients with vomiting or a Mallory-Weiss laceration, and the other occurs in patients with impaired haemostasis without any association with vomiting or a Mallory-Weiss laceration. ${ }^{4}$

Over the past few years we have encountered several necropsy cases of oesophageal haemorrhage limited to the epithelium. In these cases, there was no clinical evidence of gastrointestinal bleeding and no anticoagulants or nasogastric tubes had been used. We therefore reviewed our necropsy cases to determine the clinicopathological findings in cases with intraepithelial haemorrhage of the oesophagus (IHO). We discuss its possible aetiology and the clinicopathological features.

\section{Methods}

We reviewed necropsy records and histopathological findings in the oesophagus collected at our hospital during the period from 1990 to 1995 , and found six cases $(0.7 \%)$ of IHO from among 919 necropsy cases. The clinical records of these patients and the gross and microscopic pathology material were reviewed in detail. All the tissue samples were routinely fixed in formalin and embedded in paraffin wax. Sections ( $4 \mu \mathrm{m}$ thick) were stained with haematoxylin and eosin (H\&E).

In this paper, we use the term "intraepithelial haemorrhage" rather than "intraepithelial haematoma" since the oesophageal lesions varied in size (from a few millimetres to several centimetres). Also, in previous reports of oesophageal haematoma the authors have referred to the haematoma as being located in the submucosa or muscle layer..$^{4-7}$

Rupture of oesophageal varices and trauma are the major causes of oesophageal haemorrhage. Oesophageal bleeding secondary to oesophagitis, ulceration, or neoplasms is also well recognised. ${ }^{1-3}$ The term "oesophageal haematoma" has been referred to on several occasions in published reports, ${ }^{4-7}$ with most cases showing a submucosal or intramural mass. Such cases of oesophageal haematoma showed massive bleeding. So far, at least two aetiologies

\section{Results}

CLINICAL FINDINGS

Table 1 shows the clinical findings in the cases with IHO. The ages of the cases ranged from 42 to 82 years (average 68 years). The male to female ratio was 1:2. All cases had clinical histories of haematological disorders. The disorders included acute monocytic leukaemia in

Table 1 Clinical findings in cases with oesophageal intraepithelial haemorrhage

\begin{tabular}{|c|c|c|c|c|c|c|c|c|c|}
\hline Case & Age (years) & Sex & $\begin{array}{l}\text { Clinical } \\
\text { diagnosis }\end{array}$ & $\begin{array}{l}W B C \\
\left(\times 100 / \mathrm{mm}^{2}\right)\end{array}$ & $\begin{array}{l}\text { Platelet count } \\
\left(/ \mathrm{mm}^{2}\right)\end{array}$ & $\begin{array}{l}\text { Total bilirubin } \\
\text { ( } \mu \text { mol/l) }\end{array}$ & Shock & GI bleeding & Other \\
\hline 1 & 42 & $\mathrm{~F}$ & AMoL & 10 & 27000 & 189.8 & - & - & - \\
\hline 2 & 82 & $\mathrm{~F}$ & AA & 760 & 34000 & 188.1 & + & - & Sepsis \\
\hline 3 & 76 & $\mathrm{~F}$ & MDS & 9600 & 10000 & 52.3 & - & - & MOF \\
\hline 4 & 60 & M & AA & 2900 & 1000 & 27.4 & + & - & - \\
\hline 5 & 79 & M & MM & 12200 & 49000 & 13.7 & - & - & Sepsis \\
\hline 6 & 71 & $\mathrm{~F}$ & AMoL & 40 & 9000 & 49.6 & + & - & - \\
\hline
\end{tabular}

AA, aplastic anaemia; AmoL, acute monocytic leukaemia; GI, gastrointestinal; MDS, myelodysplastic syndrome; MM; multiple myeloma; MOF, multiple organ failure; WBC, white blood cell count. 
Table 2 Gross findings of cases with oesophageal intraepithelial haehorrhage

\begin{tabular}{llllll}
\hline Case & Distribution & $\begin{array}{l}\text { Maximum } \\
\text { length }(\mathrm{mm})\end{array}$ & Location & $\begin{array}{l}\text { Macroscopic } \\
\text { appearance }\end{array}$ & $\begin{array}{l}\text { Gastric mucosal } \\
\text { haemorrhage }\end{array}$ \\
\hline 1 & Multiple & 12 & Distal & Protruded & - \\
2 & Multiple & 21 & Distal & Flat & + \\
3 & Multiple & 13 & Distal & Flat & - \\
4 & Multiple & 79 & Distal & Protruded & + \\
5 & Solitary & 6 & Distal & Protruded & + \\
6 & Solitary & 8 & Distal & Flat & - \\
\hline
\end{tabular}

Table 3 Microscopic findings in cases with oesophageal intraepithelial haemorrhage

\begin{tabular}{|c|c|c|c|c|c|c|}
\hline Case & Erosion & Ulcer & $\begin{array}{l}\text { Degree of } \\
\text { haemorrhage }\end{array}$ & Inflammation & $\begin{array}{l}\text { Submucosal } \\
\text { scarring }\end{array}$ & $\begin{array}{l}\text { Submucosal } \\
\text { haemorrhage }\end{array}$ \\
\hline 1 & - & - & ++ & - & - & - \\
\hline 2 & - & - & + & - & - & + \\
\hline 3 & + & - & + & - & - & - \\
\hline 4 & + & - & +++ & - & - & + \\
\hline 5 & - & - & ++ & - & - & + \\
\hline 6 & + & - & + & - & - & - \\
\hline
\end{tabular}

two cases, aplastic anaemia in two, myelodysplastic syndrome in one, and multiple myeloma in one. The white blood cell count was less than $1000 / \mathrm{mm}^{3}$ in three cases. Thrombocytopenia was present in all cases. The platelet count ranged from 1000 to 49000 per $\mathrm{mm}^{3}$. However, disseminated intravascular coagulation was not diagnosed in any case. Two cases showed high total bilirubin (more than 170 $\mu \mathrm{mol} /$ litre). Clinically, shock was found in three cases, sepsis in two cases, and multiple organ failure in one case before death. There was, however, neither overt evidence of gastrointestinal bleeding such as haematemesis or melaena, nor a history of the use of nasogastric tubes or anticoagulants before death. Cardiopulmonary resuscitation was not performed in any case. Pathologically, no evidence of liver cirrhosis or oesophageal varices was found at necropsy.

PATHOLOGICAL FINDINGS

Tables 2 and 3 show the pathological findings of cases with IHO.

Grossly, the haemorrhagic area was solitary in two cases and multiple in four. The size (maximum length) raged from 6 to $79 \mathrm{~mm}$ (average $23 \mathrm{~mm}$ ). The location of IHO was the lower oesophagus in all cases (fig 1). In three cases, the haemorrhagic area was identified as a protruding lesion, and the protrusion was more obvious in larger lesions (fig 2). Mucosal haemorrhage of the stomach was also noted in three cases.

Microscopically, the lesions were clearly demarcated and they were composed of an accumulation of red blood cells (fig 3). While
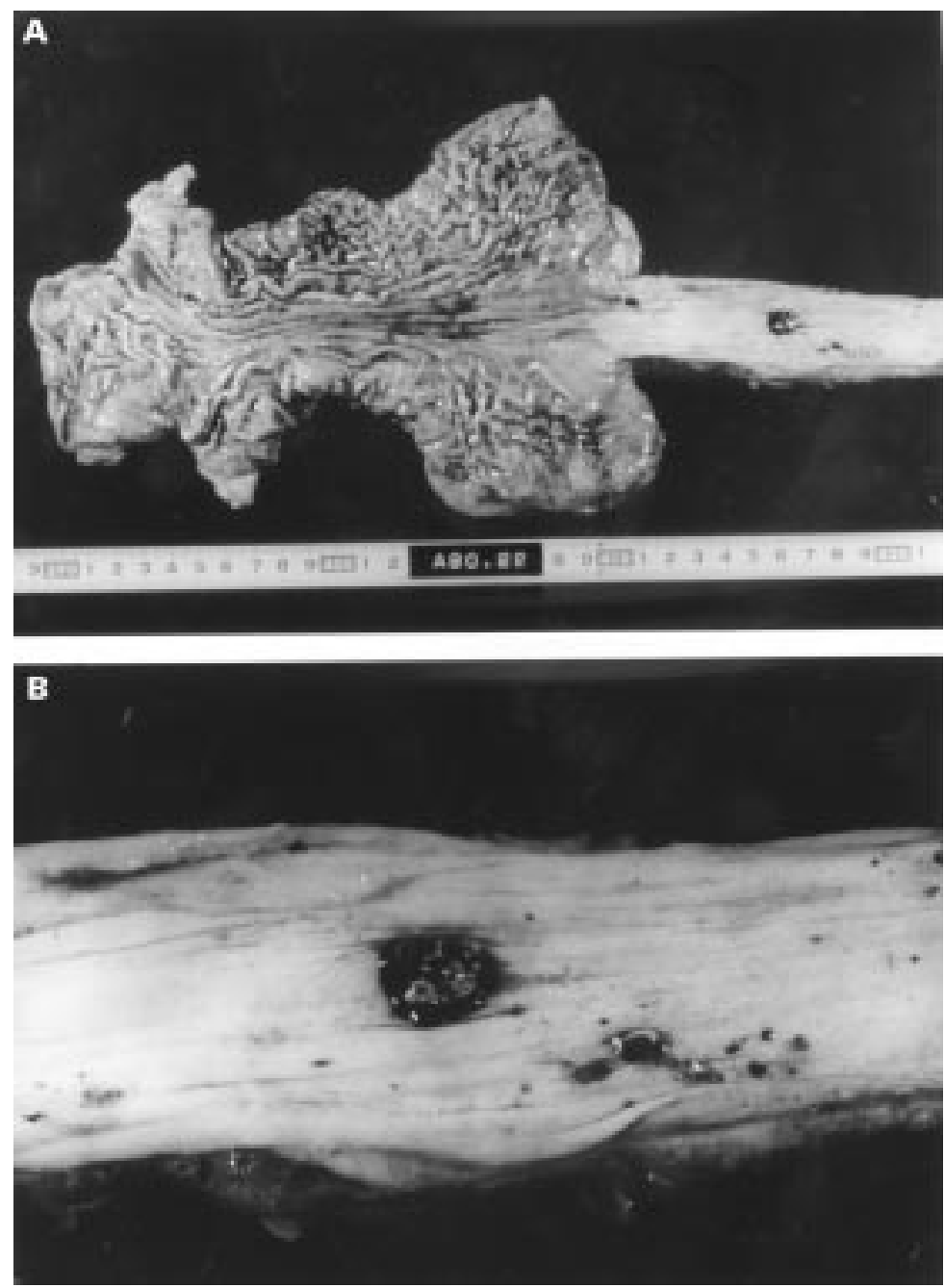

Figure 1 Gross finding of oesophageal intraepithelial haemorrhage in case 1 ( $A$, lower magnification; B, higher magnification). 

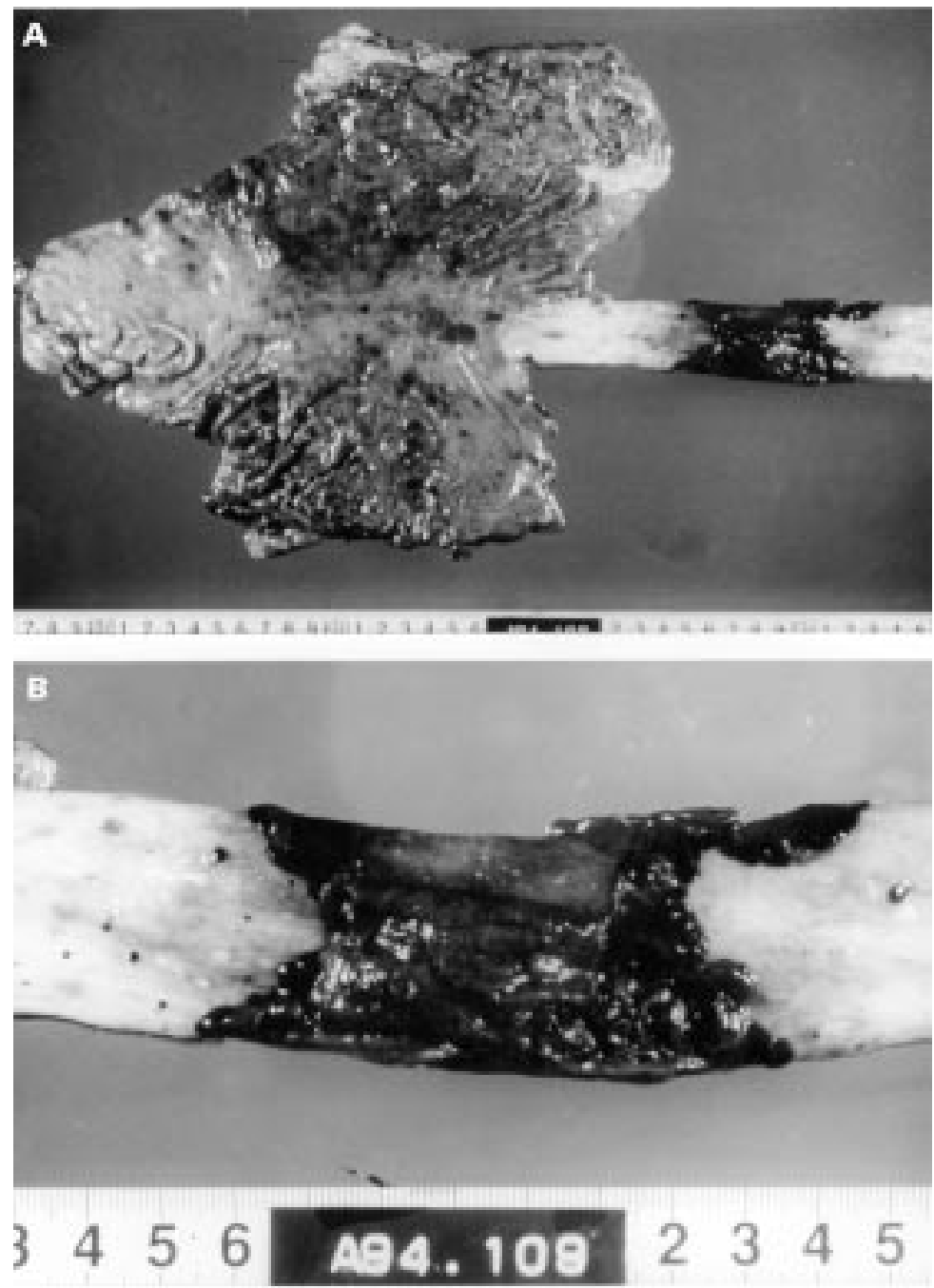

Figure 2 Gross finding of oesophageal intraepithelial haemorrhage in case 4 ( $A$, lower magnification; $B$, higher magnification).

three cases showed erosion on the surface, deep ulceration was not found in any case. Three cases showed mild and three moderate to severe haemorrhage. There were no inflammatory infiltrates of neutrophils, lymphocytes, plasma cells, or histiocytes, neither was there evidence of a submucosal healing process or scar in any case (fig 4). No evidence of microorganisms or tumour cells was found. In addition, no destruction of red blood cells was identified. In three cases, submucosal haemorrhage separate from intraepithelial haemorrhage was focally found around or beneath the intraepithelial lesion.

\section{Discussion}

Oesophageal haemorrhage or haematoma can occur with either normal or impaired haemostasis. ${ }^{4}$ An oesophageal haematoma with normal haemostasis can be related to trauma, oesophageal varices, or Mallory-Weiss syndrome. With impaired haemostasis, anticoagulants, leukaemia, or malignant lymphoma may result in such bleeding. ${ }^{48}{ }^{9}$ However, a review of published reports shows that the microscopic features in cases of oesophageal haemorrhage or haematoma have not been docu- mented in detail. Radiological and computed tomographic findings have been discussed. ${ }^{41011}$ The microscopic findings have been described in two reports, but these investigations included oesophageal lesions extending beyond the mucosa with massive necrosis of the muscular layer. ${ }^{912}$ In our six cases, there was no evidence of gastrointestinal bleeding, and the patients had not had nasogastric tubes or anticoagulants, neither had they been given cardiac massage before death. These observations suggest that the haemorrhagic lesions were spontaneous rather than mechanical or iatrogenic in origin.

It is interesting that all cases with $\mathrm{IHO}$ in this study had underlying haematological disorders, including acute monocytic leukaemia, aplastic anaemia, myelodysplastic syndrome, and multiple myeloma. All cases had thrombocytopenia, which was severe in three. In our necropsy series from 1990 to 1995, the incidence of IHO among cases with haematological disorders was 7\% (six of 84 cases). However, this type of oesophageal lesion was not identified in cases without haematological disorders. Thus IHO may be specific to such disorders. Because it has been reported that 
A
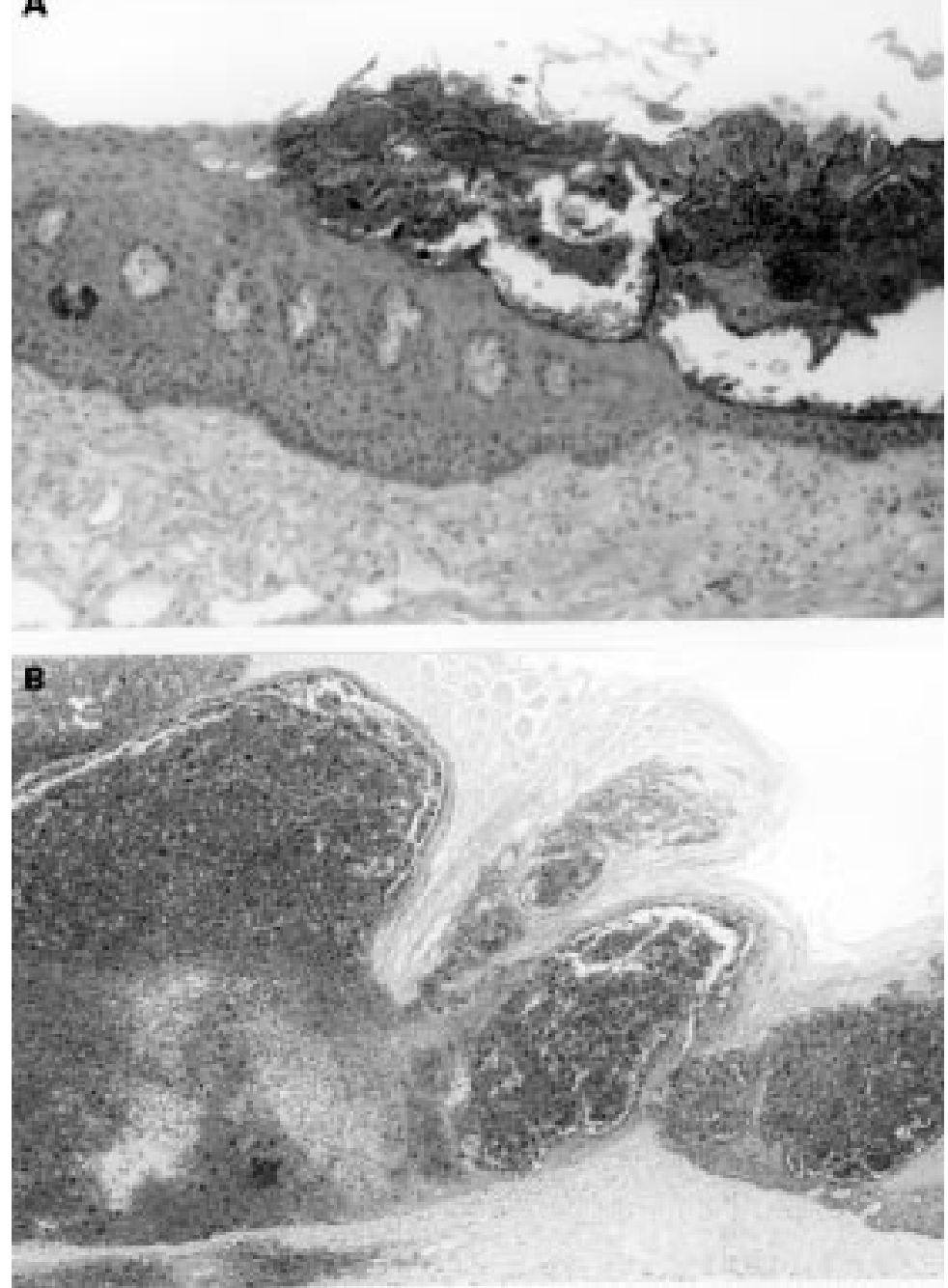

Figure 3 The demarcated lesion is composed of accumulation of red blood cells in case 3

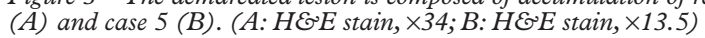

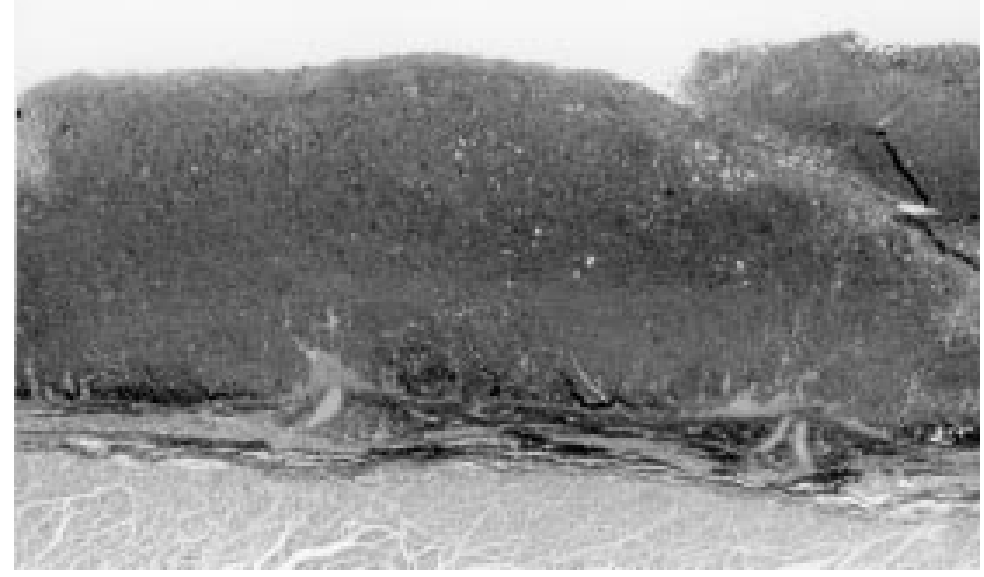

Figure 4 Focal submucosal haemorrhage is noted, but there is no evidence of inflammatory infiltrate or submucosal scar (case 4; HE E stain, $\times 4$ ) patients with leukaemia may develop massive spontaneous intraluminal oesophageal haemorrhage as a result of a bleeding diathesis, ${ }^{9}$ some cases of IHO found in this study may represent an early stage of such massive haemorrhage. In any event, these haematological disorders, including thrombocytopenia, may be important in the pathogenesis of IHO.

Both the location and the distribution of IHO differ from those of oesophageal haematomas, since the latter have been reported to occur proximally and at multiple sites, ${ }^{4}$ while IHO in our cases occurred in the distal oesophagus with solitary or multiple involvement and may thus be a different entity.

IHO seems to occur shortly before death as a terminal event in haematological disorders, because on histological examination the red cells in the lesions were not undergoing breakdown, and there was no inflammation, submucosal healing, or scar formation. In addition, to the best of our knowledge, intraepithelial haemorrhage of the oesophagus has not been reported so far. Based on these results, we proposed the term "terminal IHO" for this distinct clinicopathological lesion.

1 DeVault KR, Miller LS, Yaghsezian H, et al. Acute esophageal hemorrhage from a vagal neurilemoma. Gastroenterology 1992;102:1059-61.

2 Nwogu CE, Conlan AA. Acute submucosal esophageal hemorrhage. Ann Thorac Surg 1997;64:247-8.

3 Berliner SD, Burson L. Esophageal hemorrhage in scleroderma. Am f Gastroenterol 1966;46:477-80.

4 Shay SS, Berendson RA, Johnson LF. Esophageal hematoma. Four new cases, a review, and proposed etiology. Dig Dis Sci 1981;26:1019-24.

5 Ashman FC, Hill MC, Saba GP, et al. Esophageal hematoma associated with thrombocytopenia. Gastrointest Radiol 1978;3:115-18.

6 Atefi D, Horney JT, Eaton SB, et al. Spontaneous intramural of hematoma of esophagus. Gastrointest Endosc 1978;24: $172-4$.

7 Tschope W, Czygan P, Ritz E, et al. Intramural hematoma of the esophagus: a complication of carbon tetrachloride intoxication with acute renal failure. Clin Nephrol 1976;6: 526-8.

8 Givler RL. Esophageal lesions in leukemia and lymphoma. Am f Dig Dis 1970;15:31-6.

9 Stratemeier PH. Massive esophageal hemorrhage in leukemia. Am f Roentgenol 1977;129:1106-7.

10 Mosimann F, Brönnimann B. Intramural haematoma of the oesophagus complicating sclerotherapy for varices. Gut 1994;35:130-1.

11 Ackert JJ, Sherman A, Lustbader IJ, et al. Spontaneous intramural hematoma of the esophagus. Am 7 Gastroenterol 1989;84:1325-8.

12 Biagi G, Cappelli G, Propersi L, et al. Spontaneous intramural haematoma of the oesophagus. Thorax 1983;38: 394-5. 